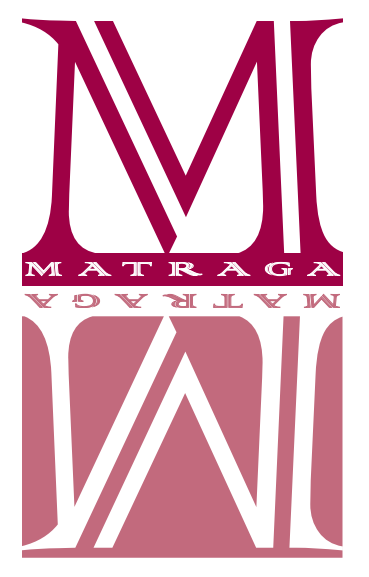

\title{
Tabus linguísticos no léxico religioso: um estudo geolinguístico com base no Atlas Linguístico do Brasil
}

\author{
Geisa Borges Costa \\ Universidade Federal da Bahia \\ https://orcid.org/0000-0002-0429-0426
}

\begin{abstract}
RESUMO
O estudo busca descrever e analisar as denominações utilizadas pelos falantes das capitais do Brasil para nomear o item lexical "diabo". Para isso, utilizaram-se inquéritos do Projeto Atlas Linguístico do Brasil (ALiB), realizados com 200 informantes, distribuídos equitativamente por ambos os sexos, em duas faixas etárias e dois níveis de escolaridade, selecionados de acordo com os critérios da Dialetologia Contemporânea. Pautando-se nos pressupostos teórico-metodológicos da Geolinguística Pluridimensional, analisou-se a primeira questão do Questionário Semântico-Lexical referente à área semântica da religião e das crenças, com o intuito de documentar a riqueza sinonímica para a variante "diabo". Os dados foram coletados através da pergunta: "Deus está no céu e no inferno está ...?". Foram registrados 506 dados lexicais, concretizados através de 39 variantes: anjo do mal, anjo mau, anticristo, besta, besta-fera, belzebu, bicho feio, bicho ruim, cão, capeta, capiroto, chifrudo, coisa, coisa ruim, cramulhano, criatura, cruz-credo, demo, demônio, desgraça, diabo, didi, encardido, enxofre, estrela vermelha, inimigo, lúcifer, maligno, mefítico, príncipe dos céus, rabudo, sapirico, satã, satangoso, satanás, sujo, tibinga, tinhoso, troço. A análise semântico-lexical revelou uma correspondência entre os recursos linguísticos substitutivos do referente diabo e os tabus linguísticos, registrados através de processos metafóricos, eufemísticos e disfemísticos.
\end{abstract}

PALAVRAS-CHAVE: Léxico. Tabus Linguísticos. Atlas Linguístico do Brasil

\section{Linguistic Taboos in The Religious Lexikon: A Geolinguistic Study Based on Brazil's Linguistic Atlas}

\section{ABSTRACT}

The study seeks to describe and analyze the denominations used by speakers of the capitals of Brazil to name the lexical item "devil". For this, surveys of the Atlas Linguistic Project of Brazil (ALiB) were used, carried out with 200 informants, distributed equally by both sexes, in two age groups and two levels of education, selected according to the criteria of Contemporary Dialectology. Based on the theoretical and methodological assumptions of Pluridimensional Geolinguistics, the first question of the Semantic-Lexical Questionnaire regarding the semantic area of religion and beliefs was analyzed, in order to document the synonymic richness for the devil variant. The data was collected through the question: "God is in heaven and in hell is ...?". 506 lexical data were recorded, realized through 39 variants: angel of evil, evil angel, antichrist, beast, beastbeast, beetle, ugly animal, bad animal, dog, devil, capirot, horned, thing, bad thing, cramulhano, creature, cross-creed, demo, demon, disgrace, devil, didi, grimy, sulfur, red star, enemy, lucifer, evil, mephitic, prince of the heavens, rabudo, sapirico, satan, satangoso, satan, dirty, tibinga, tinhoso, change. The semantic-lexical analysis revealed a correspondence between the substitute linguistic resources of the devil referent and the linguistic taboos, registered through metaphorical, euphemistic and dysphemistic processes.

KEYWORDS: Lexicon. Linguistic Taboos. Linguistic Atlas of Brazil 


\section{Introdução}

O nível lexical da língua é a área da linguagem que melhor reflete a realidade cultural e social de uma comunidade. É pela palavra que o indivíduo vai conhecendo o universo à sua volta e o mundo se revela para ele, que o percebe através de diferentes sentidos, sensações, sentimentos, objetos, os quais são nomeados e reconhecidos por esses nomes. Desse modo, os elementos do mundo biossocial são registrados e identificados, constituindo-se em um universo significativo para o falante.

Em sua ligação com o mundo exterior, a palavra identifica o ser humano, ajuda-o a construir vínculos sociais, culturais, religiosos e afetivos, revelando-se como um modo de aproximação ou distanciamento entre as pessoas, que se afligem, angustiam-se, entristecem-se ou se alegram ao ouvir determinadas palavras.

$\mathrm{O}$ aspecto lexical da língua é considerado o retrato da cultura de um povo, refletindo aspectos vinculados às experiências sociais e culturais de uma comunidade, pois, ao escolher formas linguísticas para nomear os referentes do mundo físico e do universo simbólico, o indivíduo revela não somente a sua percepção da realidade, mas compartilha valores, práticas culturais e crenças do grupo social em que se enquadra.

As realizações lexicais dos indivíduos expressam sua visão de mundo, suas crenças, suas ideologias, seus valores e a norma linguística aprendida através das práticas socioculturais presentes em seu grupo social, que, geralmente, mantêm entre si uma identidade linguística.

Tendo em vista que a língua é também um produto cultural da comunidade, e, dentre os níveis da língua, o léxico é um dos mais afetados pelas influências socioculturais, o estudo sobre o léxico poderá evidenciar aspectos bastante significativos da correlação entre a língua e a diversidade cultural.

As questões que motivaram esta pesquisa foram: de que forma se apresenta a produtividade das variantes para designar aspectos do campo léxico-semântico das religiões e das crenças, mais particularmente, do item lexical "diabo" nas capitais do Brasil? É possível evidenciar indícios de tabus linguísticos no vocabulário religioso dos falantes das capitais brasileiras?

Para responder a esses questionamentos, tem-se como objetivos do trabalho:

- descrever e analisar a produtividade das variantes referentes ao item lexical "diabo", documentadas pelo Projeto Atlas Linguístico do Brasil (ALiB);

- identificar a presença de tabus linguísticos no vocabulário religioso dos falantes das capitais brasileiras.

A escolha do campo semântico da religião e das crenças deve-se, sobretudo, à possibilidade de se revelarem, através dos dados, aspectos míticos e folclóricos do imaginário e da cultura popular e motivações histórico-religiosas evidenciadas através das realizações linguísticas de grupos sociais diversificados.

\section{Tabus linguísticos no campo religioso}

No campo linguístico, é importante registrar que "diabo" constitui-se em uma lexia tabu. A palavra "tabu”, conforme Guérios (1979), tem sua origem nas línguas do ramo malaio-polinési- 
co, significando sagrado, proibido, consagrado, impuro. Os tabus podem estar associados a objetos (que não devem ser tocados), lugares (que não devem ser visitados), ações (que não devem ser praticadas) e palavras (que não devem ser ditas).

O dicionário Houaiss (2009, verbete "tabu”) da língua portuguesa traz as seguintes acepções para tabu:

1 - instituição religiosa que, atribuindo caráter sagrado a determinados seres, objetos ou lugares, proíbe qualquer contato com eles [a violação desse interdito acarreta, supostamente, castigo divino, que pode recair sobre o culpado ou sobre seu grupo]; 2 - interdição cultural e/ou religiosa quanto a determinado uso, comportamento, gesto ou quanto à linguagem $<$ o povo fez da palavra diabo um tabu linguístico >; 3 - proibição imposta por costume social ou como medida protetora; 4 - proibido por crença de ordem sobrenatural; 5 - que não pode ser usado, feito, tocado, ou pronunciado por crença, respeito ou pudor.

Ao analisar as definições para tabu expressas no dicionário em foco, um fato inquestionável é a relação que todos os conceitos e acepções para tabu estabelecem com o sistema de crenças e valores da sociedade, havendo sempre uma motivação de ordem religiosa ligada ao sobrenatural ou ao código moral. Além disso, o tabuísmo está intrinsecamente associado à linguagem, já que existe uma interdição social e cultural quanto ao uso de determinadas palavras-tabu, consideradas indecentes, ofensivas, imorais, grosseiras, vulgares, antirreligiosas ou até mesmo sagradas.

Os tabus linguísticos fazem parte da cultura e do cotidiano ao longo da história das civilizações humanas. São termos que se revestem de diversas cargas simbólicas, a depender do teor do vocábulo, a ponto de as pessoas acreditarem que seu uso pode trazer malefício ou castigo. Muitas expressões-tabu também são estigmatizadas pela sociedade, o que se reflete na avaliação social do falante que a utiliza.

Essas palavras proibidas são, em geral, substituídas por outras, já que os indivíduos evitam utilizá-las, e, em seu lugar, abundam eufemismos e neologismos que se encarregam de evitar o mal-estar que poderá ser causado por essas expressões.

Guérios (1979) distingue dois tipos de tabus: o próprio e o impróprio. O primeiro consiste na proibição de dizer certo nome ou palavra, aos quais se atribui poder sobrenatural e cuja infração causa infidelidade e desgraça e o segundo seria a proibição de dizer qualquer expressão imoral ou grosseira. A primeira acepção para tabu está ligada a valores mágico-religiosos ou de crença, e a segunda a questões morais ou de natureza sentimental. $\mathrm{O}$ autor apresenta a seguinte classificação para os tabus: tabus em nomes de pessoas; tabus em nomes de parentes; tabus em nomes de autoridades; tabus em nomes religiosos; tabus em nomes de mortos; tabus em nomes de animais; tabus em nomes de membros do corpo humano; tabus em nomes de lugares e circunstâncias; tabus em nomes de doenças e defeitos físicos; tabus em nomes de alimentos; tabus em nomes vários.

A tese intitulada À guisa de uma tipologia para os tabus linguísticos - proposta para um glossário, Almeida (2007) buscou fazer uma análise comparativa dos tabus linguísticos presentes nas respostas apresentadas pelos sujeitos em seis atlas estaduais brasileiros. Tomando por base o questionário semântico-lexical do Projeto Atlas Linguístico do Brasil, a autora selecionou seis 
campos semânticos para a realização da análise: fenômenos atmosféricos, corpo humano, religião e crenças, doenças, ciclos da vida, convívio e comportamento social.

No que se refere à área semântica da religião e das crenças, Almeida (2007) analisou os termos utilizados pelos informantes do Atlas Lingüístico do Paraná para responder à questão sobre a entidade-tabu que anima o redemoinho. A pergunta obteve, segundo a autora, vinte e uma variantes linguísticas: saci (16 ocorrências), capeta (12 ocorrências), diabinho (10 ocorrências), bichinho (quatro ocorrências), sacizinho (três ocorrências), cão (três ocorrências), capetinha (duas ocorrências), bicho (duas ocorrências), aquilo, bicho feio, bicho ruim, caramujo, chifrudo, coisa feio, demônio, demoninho, fantasma, pé-de-pato, rabudo, o que não presta, tentação, coisinha feio (uma ocorrência de cada uma dessas).

Conforme Almeida (2007), os entrevistados detiveram-se mais em descrever do que em propriamente nomear a entidade, pois, segundo a crença popular, ao se pronunciar o nome do diabo ou do saci, eles podem aparecer. Ela acrescenta ainda que o fato de as lexias diabo e saci-pererê quase não ocorrerem pode ser considerado um exemplo típico de tabu. Consideramos, entretanto, que essa afirmação pode ser questionada, pois o número de ocorrências da lexia saci foi bastante significativo, e não parece que o tabu linguístico possa estar associado ao qualificativo pererê. Outra análise passível de contestação é a designação que a autora dá para saci e sacizinho como variantes diferentes, pois, no corpus do trabalho, elas não assumem significados distintos.

Os nomes religiosos são, sem dúvida, uma grande fonte de tabus, até pelo temor que muitos creditam a eles, o que faz com que seja considerada uma falta de respeito a pronúncia de alguns desses termos. Algumas passagens da Bíblia Sagrada são categóricas, quando dizem "Não tomarás o nome do teu Deus em vão, porque não ficará impune aquele que tomar o seu nome por uma coisa vã" (DEUTERONÔMIO 5:11).

Muitos religiosos tomam esse trecho como uma ordem expressa para que não se pronuncie o nome de Deus, e assim o fazem, considerando a consequência advinda no final do versículo. Desse modo, a religião criou uma cultura de que não se deve proferir um nome tido como sagrado, poderoso e temido. Segundo Guérios (1979), os rabinos e os padres gregos qualificavam o nome de Deus como "nome por excelência, nome único, nome glorioso, nome terrível, nome secreto e misterioso, nome separado, nome escrito e não proferido, etc".

Os tabus em nomes de espíritos malignos, citados por Guérios (1979), são fatos de grande interesse para esta pesquisa. Segundo o autor, evitam-se as palavras diabo, demônio, satanás, sendo esses nomes substituídos por inúmeros outros, que Guérios (1979) classifica assim:

- os "deformados", de propósito, em sua forma fônica ou morfológica (diacho, dialho, diamo, dianho, demo, satã, satão);

- os metalexismos, que se subdividem em:

- eufêmicos hipocorísticos (diabinho, diabrete, demoninho, maioral, compadre);

- antifrásticos (na Armênia - os melhores que nós; no russo - o justo, o rei da floresta);

- disfêmicos (bicho, bicho-preto, cão, tinhoso, cão-tinhoso, cão miúdo, grão-tinhoso, o coisa, coisa-má, coisa-ruim, malvado, mofento, mofino, porco, sujo, danado, arrenegado, condenado, excomungado, maldito, lobo-infernal, maligno, malino, inimigo, pai-da-mentira, pai-do-mal, pecado, porco-sujo, bicho-feio, bicho-negro, espírito maligno, espírito-imundo, 
anjo mau, anjo das trevas, tentador, tentador das almas, anjo rebelde, anjo das trevas, gênio das trevas, gênio do mal, fedorento, porqueira, espírito mau, daninho, mofino, veneno, moleque, moleque-do-surrão, tentação, bicho mau, imundo, porco-imundo, o-lá-debaixo, etc);

- qualificativos (canhim, manquinho, sarnoso, sarnento, coxo, canhoto, canheta, tisnado, mal-encarado, feio, pé-de-cabra, chifrudo, carnudo, rabudo, pé-de-peia, pé-de-pato, bingudo, patudo, rabão, esticado, beiçudo, careca, carocho, guedelha, barbas-de-chibo, pé-torto).

Guérios (1979) traz ainda outras substituições para a lexia tabuizada, como bodego, zangão, capeta, coisa, indivíduo, não-sei-que-diga, que-diga, tição, caneco, cabra velho, bode preto, gato preto, exu, cujo, o-da-carapuça vermelha, desinquietador das almas, enredador, tal coisa, lembrando que essas substituições podem ser feitas por meio de pronomes demonstrativos, como o dêitico "ele", utilizado por falantes da língua portuguesa.

Aspecto a ser destacado na obra de Guérios (1979) é que ele traz bastantes exemplos de vocábulos tabus em diversas outras línguas, havendo pouca exemplificação na língua portuguesa, o que demonstra que o estudo das expressões tabuizadas no português ainda era bastante incipiente à época da publicação dessa obra, que pode ser considerada um estudo pioneiro na descrição e análise dos tabus linguísticos.

O estudo do tabu passou a oferecer meio privilegiado para a compreensão de diferentes culturas, linguagens e visões de mundo dos mais diversos grupos sociais, podendo revelar a estreita relação que existe entre língua e cultura, uma vez que os tabus presentes na linguagem humana se constituem em práticas não apenas linguísticas, mas também em práticas culturais, na medida em que, conforme explica Preti (1984, p. 286), “em nome de uma ética vigente, proíbem-se ou liberam-se palavras, processam-se julgamentos de bons ou maus termos, apropriados ou inadequados aos mais variados contextos e tabus linguísticos aparecem em decorrência de tabus sociais.”

Os tabus linguísticos estão presentes em todas as culturas humanas, tendo como motivação principal os julgamentos sociais que os falantes fazem sobre algumas palavras consideradas indecorosas, profanas, repugnantes, ofensivas, o que evidencia a atuação de fatores extralinguísticos e de componentes culturais no comportamento linguístico dos indivíduos.

\section{Metodologia}

O trabalho constitui-se a partir de um segmento do Questionário Semântico-Lexical (QSL) do Projeto Atlas Linguístico do Brasil (ALiB), considerando-se as respostas dadas pelos informantes para a primeira pergunta referente ao campo semântico Religiões e Crenças (Cf. Comitê Nacional Do Projeto ALiB, 2001).

A questão 147 do QSL foi formulada, no âmbito do Projeto Atlas Linguístico do Brasil, com o fim de documentar a riqueza sinonímica utilizada pelos indivíduos para nomear o item lexical "diabo". Desse modo, perguntou-se ao informante: "Deus está no céu, e no inferno está ?"

Para este estudo, utilizaram-se inquéritos realizados com 200 informantes - 100 homens e 100 mulheres - das vinte e cinco capitais brasileiras: quatro homens e quatro mulheres por 
capital; dois homens e duas mulheres pertencentes à Faixa I - dos 18 aos 30 anos; dois homens e duas mulheres correspondentes à Faixa Etária II - dos 50 aos 65 anos; dois níveis de escolaridade: nível fundamental incompleto e nível universitário, conforme metodologia adotada pelo Projeto ALiB.

Para cada variante levantada nos inquéritos, foram feitas consultas nos seguintes dicionários de língua portuguesa: Aulete digital (2013), de Caldas Aulete; Novo Dicionário Aurélio da Língua Portuguesa (2009), de Aurélio Buarque de Holanda Ferreira; Dicionário Houaiss da Língua Portuguesa (2009), de Antonio Houaiss e Mauro Villar. A consulta permitiu observar: 1) se a forma lexical é registrada; 2) quais os significados que são atribuídos a essas palavras; 3 ) se outros itens lexicais sinônimos são trazidos pelos autores.

\section{Análise dos dados}

No âmbito do Questionário semântico-lexical do Atlas Linguístico do Brasil, os informantes foram inquiridos com a seguinte pergunta: "Se Deus está no céu, no inferno está..." (COMITÊ NACIONAL, 2001). As respostas apresentadas demonstraram uma gama de variantes para nomear o referente "diabo": anjo mau, anticristo, besta-fera, belzebu, bicho ruim, cão, capeta, capiroto, chifrudo, coisa ruim, cramulhano, criatura, demo, demônio, desgraça, diabo, encardido, enxofre, inimigo, lúcifer, príncipe dos céus, rabudo, sapirico, satã, satanás, sujo, troço.

Conforme Antunes (2012, p. 136),

as informações a que podemos ter acesso em um dicionário ultrapassam o limite de sua configuração linguística para abranger o domínio das representações culturais ou da memória social que a língua naturalmente registra. $\mathrm{O}$ vocabulário de uma língua, para além de sua natureza estritamente linguística, traz também elementos que representam a cultura, a memória e a história de um povo, seu sistema de valores e crenças, podendo ser entendido como um testemunho daquilo que foi experimentado e vivido.

Nessa perspectiva, foi realizada uma pesquisa em três dicionários da língua portuguesa, um dicionário etimológico e um dicionário do folclore brasileiro com o intuito de se observar o significado atribuído pelos lexicógrafos para os temos utilizados pelos informantes como referência à lexia "diabo".

Algumas variantes utilizadas pelos informantes para nomear "o ser que está no inferno" não constam nos dicionários consultados. Outras foram dicionarizadas com outras acepções. $\mathrm{O}$ Quadro 1, posto a seguir, possibilita a visualização das lexias dicionarizadas, não-dicionarizadas e dicionarizadas com significados diferentes daqueles atribuídos pelos informantes.

Os dados encontrados no corpus foram organizados de acordo com critérios semânticos, o que permitiu dois agrupamentos: nomes de origem religiosa ou mitológica, metáforas, eufemismos e disfemismos.

O primeiro grupo diz respeito às formas lexicais que tem sua origem ou seu uso relacionado às concepções cristãs sobre "o ser que está no inferno", incluindo também neste grupo os termos que são atribuídos à mitologia grega. 
QUADRO 1. Formas lexicais dicionarizadas e não-dicionarizadas

\begin{tabular}{|c|c|c|c|}
\hline \multicolumn{2}{|c|}{ Formas lexicais dicionarizadas } & $\begin{array}{l}\text { Formas lexicais não } \\
\text { dicionarizadas }\end{array}$ & $\begin{array}{c}\text { Formas lexicais dicionarizadas } \\
\text { com outras acepcões }\end{array}$ \\
\hline $\begin{array}{l}\text { anjo mau } \\
\text { anticristo } \\
\text { belzebu } \\
\text { bicho ruim } \\
\text { cão } \\
\text { capeta } \\
\text { capiroto } \\
\text { chifrudo } \\
\text { coisa-ruim }\end{array}$ & $\begin{array}{l}\text { cramulhano } \\
\text { demônio } \\
\text { demo } \\
\text { diabo } \\
\text { inimigo } \\
\text { lúcifer } \\
\text { satã } \\
\text { satanás } \\
\text { sujo }\end{array}$ & $\begin{array}{l}\text { príncipe dos céus } \\
\text { sapirico }\end{array}$ & $\begin{array}{l}\text { besta-fera } \\
\text { criatura } \\
\text { desgraça } \\
\text { encardido } \\
\text { enxofre } \\
\text { troço }\end{array}$ \\
\hline
\end{tabular}

Fonte: Autoria própria

O segundo grupo refere-se aos vocábulos que foram empregados para denominar o "diabo", através de processos metafóricos, considerando-se os eufemismos e disfemismos como casos especiais de metáforas, embora os limites entre essas categorias sejam bastante fluidos e controversos, o que faz com que alguns estudiosos as considerem como duas faces de uma mesma moeda, como alerta o pesquisador espanhol Chamizo Domínguez (2004, p. 45):

El que una palabra dada (o una expresión, en su caso) sea sentida por los hablantes como un eufemismo o como un disfemismo no depende de la palabra en sí, sino del contexto, del uso que se haya hecho de dicha palabra o de las intenciones de los hablantes'.

QUADRO 2. Distribuição semântica dos dados para "diabo"

\begin{tabular}{|l|ll|}
\hline \multicolumn{1}{|c|}{$\begin{array}{c}\text { Nomes considerados } \\
\text { religiosos ou mitológicos }\end{array}$} & \multicolumn{2}{|c|}{$\begin{array}{c}\text { Metáforas, Eufemismos e } \\
\text { Disfemismos }\end{array}$} \\
\hline anjo mau & bicho ruim & encardido \\
anticristo & capeta & enxofre \\
belzebu & capiroto & inimigo \\
besta-fera & chifrudo & rabudo \\
demônio & coisa ruim & sapirico \\
diabo & cramulhano & satã \\
lúcifer & criatura & sujo \\
príncipe dos céus & demo & troço \\
satanás & desgraça & \\
\hline
\end{tabular}

Fonte: Autoria própria

Conforme se pode observar no Quadro 2, alguns dados lexicais referentes às respostas para a Questão 147 do QSL “Se Deus está no céu, no inferno está...?”, revelam indícios de tabus na linguagem religiosa dos informantes das capitais brasileiras.

\footnotetext{
1 Para que uma determinada palavra (ou uma expressão, neste caso) seja sentida pelos falantes como um eufemismo ou como um disfemismo não depende da palavra em si, mas do contexto, do uso que se faça da palavra ou das intenções dos falantes. (Tradução nossa).
} 
Alguns trechos dos inquéritos do ALiB mostram que muitos informantes se sentem desconfortáveis para proferir o nome "diabo" e parecem crer que a simples pronúncia do termo pode representar uma invocação ao espírito do mal ou uma reverência àquele que é considerado o anjo rebelde. Desse modo, não raro recorrem a metáforas ou eufemismos para responderem à pergunta 147 do QSL do Projeto ALiB. Conforme Souto Maior (1975), a causa pela abundância de eufemismos para o "diabo" foi o medo que se tinha antigamente de pronunciar seu nome. Havia uma antiga crença que dizia não ser bom falar seu nome, pois ele podia aparecer na mesma hora, trazendo infelicidade para a família.

INQ. - Deus está no céu e no inferno está quem?

INF. - Xi...tô fora. Não conheço essa linguagem não. É o "inimigo".

INQ. - Conhece algum outro nome para ele?

INF. - Aff... tem vários nomes pra esse cara aí, viu? Tem vários. Tem que falar declarado mesmo? Eu sei que ele vai gostar de chamar o nome dele, né? É... é o "estrela vermelha".

(QSL, Informante 1, homem, faixa etária I, nível de escolaridade fundamental, São Paulo - SP).

Em outros depoimentos, parece haver uma resistência dos informantes não só em pronunciar o termo "diabo", como também outras palavras que representam o "ser maligno". A palavra traz à tona uma carga de valores negativos presentes no imaginário das pessoas, principalmente daquelas que já podem ter ouvido muitas histórias e episódios sobre o poder destruidor dessa "entidade maldita". Alguns excertos das entrevistas do ALiB mostram que determinados informantes evitam pronunciar os nomes existente para identificar "o ser que está no inferno":

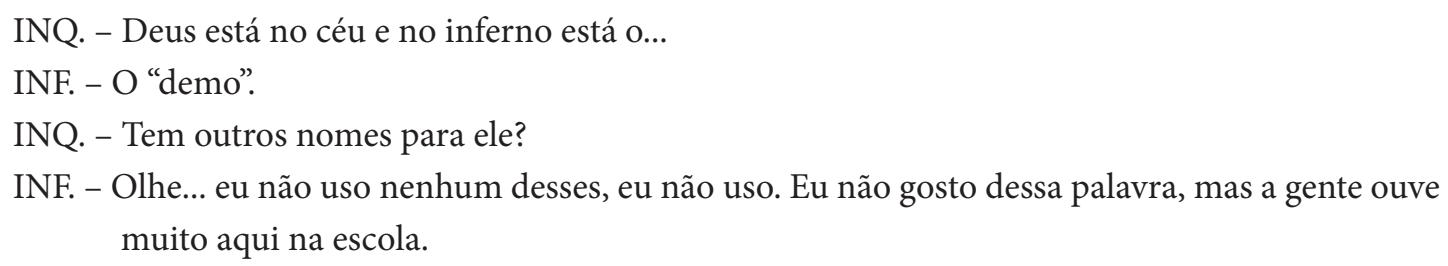

(QSL, Informante 8, mulher, faixa II, nível de escolaridade universitária, Curitiba - PR).

As crenças religiosas são responsáveis pela manifestação de uma gama de tabus no âmbito da linguagem. Muitas palavras advindas do campo religioso são tidas como impuras e causadoras de malefícios e, por isso, não devem ser proferidas.

Essa ideia difundida, principalmente, pelas religiões cristãs leva o falante a evitar o uso dos termos tabus, substituindo-os por outros itens lexicais criados através de diversos recursos linguísticos, como metáforas, metonímias e eufemismo. Isso ficou bastante evidenciado nas respostas para a questão 147, em que os informantes das capitais brasileiras utilizaram diversas variantes eufêmicas para nomear o referente "diabo". Dentre estas, podem-se citar: anticristo, didi, estrela vermelha, inimigo, príncipe dos céus, satã.

Os tabus linguísticos podem, portanto, ser identificados enquanto fatos sociais e culturais, uma vez que refletem todo um sistema de valores, hábitos e crenças da comunidade. 


\section{Considerações finais}

Este trabalho teve como objetivo principal descrever e analisar, sob a perspectiva diatópica, a produtividade das variantes lexicais para a primeira questão da área semântica Religiões e Crenças, documentada pelo Projeto Atlas Linguístico do Brasil nas capitais nordestinas.

A investigação seguiu as diretrizes teóricas e metodológicas da Geolinguística Pluridimensional Contemporânea. Os dados lexicais que integram o corpus do trabalho foram coletados através de 200 entrevistas do Questionário Semântico-Lexical realizadas nas vinte e cinco capitais brasileiras que integram o Projeto ALiB.

No que tange à questão "Se Deus está no céu, no inferno está...?", as unidades lexicais apuradas para o referente "diabo" correspondem a 26 formas lexicais, o que demonstra a produtividade da variação relacionada ao conceito compreendido por este item lexical.

O estudo possibilitou o conhecimento de importantes elementos linguísticos e sociais manifestados através do campo semântico-lexical das religiões e das crenças. As marcas culturais dos falantes das capitais brasileiras estão impressas nos elementos lexicais utilizados para nomear "o ser que está no inferno".

As variantes documentadas demonstraram ser o termo "diabo" uma lexia tabu, pois os informantes, ao responderem à questão, utilizaram muitas formas metafóricas para substituí-lo, como: coisa ruim, inimigo, anticristo, sujo, encardido.

No campo religioso, não é raro o falante utilizar termos metafóricos, eufemísticos e disfemísticos como um meio de não proferir determinadas palavras consideradas pecaminosas ou malditas, as quais são fortemente rejeitadas e, normalmente, sofrem sanção social.

Nas mais variadas culturas, existe a crença de que a simples pronúncia de algumas palavras pode atrair para as pessoas toda sorte de males, devendo-se evitar o uso do termo, a fim de afastar os perigos que ele pode trazer.

Os tabus linguísticos podem, portanto, ser identificados enquanto fatos sociais e culturais, uma vez que refletem todo um sistema de valores, hábitos e crenças da comunidade.

\section{REFERÊNCIAS}

ALMEIDA, Laura de. À guisa de uma tipologia para os tabus lingüísticos: proposta para um glossário. 2007. 193 f. Tese (Doutorado em Linguística) - Faculdade de Filosofia, Letras e Ciências Humanas, Universidade de São Paulo, São Paulo, 2007.

ANTUNES, Irandé. Território das palavras: estudo do léxico em sala de aula. São Paulo: Parábola, 2012.

AULETE, Caldas. Aulete digital: dicionário contemporâneo da Língua Portuguesa. Lexicon: Rio de Janeiro, 2013.

BÍBLIA SAGRADA. Trad. João Ferreira de Almeida. São Paulo: Sociedade Bíblica do Brasil, 1969.

CHAMIZO DOMÍNGUEZ, Pedro. La función social e cognitiva del eufemismo y del disfemismo. Revista

Panace@, Málaga, v. 15, p.45-51, mar. 2004. 
COMITÊ NACIONAL DO PROJETO ALiB. Atlas Linguístico do Brasil: Questionários 2001. Londrina: EDUEL, 2001.

GUÉRIOS, Mansur. Tabus Lingüísticos. São Paulo: Nacional, 1979.

HOUAISS, Antônio; VILLAR, Mauro.1 $1^{\mathrm{a}}$ ed. Dicionário Houaiss da Língua Portuguesa. Rio de Janeiro: Objetiva, 2009.

PRETI, D. A gíria e outros temas. São Paulo: T. A. Queiroz, 1984. 